\title{
Prevalence of Emotional Disturbance in Children with Hearing Impairment and Intellectual Disability
}

\section{Qasir Abbas*}

Department of Psychiatry, Institute of Behavioral Sciences, Dow University of Health Sciences, Karachi,Pakistan

\begin{abstract}
Present study aims to investigate the prevalence of emotional disturbance among children with hearing impairment and intellectually disabled. Sample of 67 children was collected from different rehabilitation centers of Karachi, Pakistan. Intellectually disabled were 35 and with hearing impairment were 32 children. Sample age range was 12 to 18 years with mean age of 14.98 years. One to one session was conducted with parents in order to get history of presenting problem of the child. After getting demographic information, proper instructions were given to a child and then Human Figure Drawing Test (HFD, Koppitz) was administered individually. Data was scored according to manual and was statistically analyzed. Findings reported the prevalence of emotional disturbance was found statistically significant in both intellectually disabled and children with hearing impairment. Further protocols showed various indications of psychiatric disorders i.e. poor integration of personality, intense anxieties, feeling of insecurity and hopelessness, aggression, impulsivity and poor self-image. It is concluded that intellectually disabled and children with hearing impairment are at high risk of emotional disturbance that is valid indication of psychiatric disorders.
\end{abstract}

Keywords: Emotional disturbance; Hearing impairment; Intellectual disability

\section{Introduction}

Individual with disability are part of our society and culture. Occurrence of this problem is not only in Pakistan but it also exists throughout the world. According to World Report on Disability (2011) generated by World Health Organization and the World Bank together, more than one billion people are living with disability. In Pakistan, the prevalence of disability is calculated $2.5 \%$ of whole population which is comparatively lower (National Policy for Persons with Disabilities, 2002) $[1,2] .7 .40 \%$ out of $2.5 \%$ disabled population are living with hearing impairment and $14 \%$ are mentally handicapped. Although intellectual disability and hearing impairment are different kind of problems but they are similar in creating emotional disturbance among children. Prevalence of emotional problems is common among children with hearing impairment and intellectual disability [3]. Because both type of problems affect negatively children's emotional well-being. Similarly, Simmons reported disabled children are more vulnerable to emotional distress [4].

In recent years, people perceptions about the disability is going to change and they started to believe that individuals with disability can do something or they perform well in their different aspect of life by using those abilities that are blessed. But half century back this perspective was different. Mostly people were believed that individuals don't perceived emotional disturbance due to his/her disability and inadequate or unacceptable behaviors of person are part of his/her disability. Some were believed that children with hearing impairment have poor or deficient learning disabilities [5]. This perspective provided negative idea to people and they started to ignore disabled people because their efforts are useless. However, some believed there is no opportunity of treatment and few of them denied accepting the disability in child [6]. Ultimately, these things revealed into stigmatization and discrimination. With the passage of time, professionals and experts totally rejected these perspectives when they found disabled people can perform well and their abilities are being affected due to mental health problems. Even prevalence rate of mental health problems was found higher in them than normal population.
Some authors investigated this rate $15 \%$ to $41 \%$ among disabled people $[7,8]$. Fletcher et al. investigated this rate up to $30 \%$ and sever emotional problems were found among intellectually mild disabled children at age of 4 years by Baker et al. $[9,10]$.

Intellectual disability means person's level of intellectual functioning is below 70 and this level is further classified into mild, moderate, severe and profound intellectual functioning. General medical problems in intellectual disabled children are epilepsy, cerebral palsy, lower weight at time of birth and premature and common psychological problems are behavioral, intellectual, social and developmental disorders [1113]. According to Lidz, intellectually disabled children perceived lower sense of mastery, competency and poor performance and other problems are unclear speech, motor issues, difficulty in daily living skills and learning difficulties [14,15]. Speech problem is one major cause of emotional disturbance in these children. When people and sometimes parents could not understand them and their needs and wishes are not fulfilled properly that becomes very distressing and hurting for a child and children usually develop emotional and behavioral problems likewise anxiousness, stubbornness and aggression [16]. These issues cause emotional disturbance and emotional distress leads to various psychiatric illnesses.

Generally, hearing impairment means deficiency or impairment in sense of hearing and these things interferes or cause difficulty to grasp knowledge and skills. Due to lack of awareness people have different

*Corresponding author: Qasir Abbas, Clinical Psychologist, Dr. A. Q Khan Center, Institute of Behavioral Sciences, Suparco Road Karachi, Karachi, Sindh 72000, Pakistan, Tel: +92-3337683133; Email: qasirabbas47@yahoo.com

Received October 26, 2015; Accepted January 21, 2016; Published January 28, 2016

Citation: Abbas Q (2016) Prevalence of Emotional Disturbance in Children with Hearing Impairment and Intellectual Disability. J Psychiatry 19: 350 doi:10.4172/2378-5756.1000350

Copyright: (C) 2016 Abbas Q. This is an open-access article distributed under the terms of the Creative Commons Attribution License, which permits unrestricted use, distribution, and reproduction in any medium, provided the original author and source are credited 
views and perceptions about children with hearing impairment. According to an observation, in our culture usually people used term "deaf and dumb" for people with hearing impairment, it means "not being able to hear and being stupid" but historically this term is explained as "not able to hear and not able to speak" and some people perceived these children are with limited abilities and cognitively deficient [17]. Misinterpretations and labeling by people cause stigmatization and discrimination. Because of this they also perceived low level of tolerance, become impulsive and hyperactive when their needs are not gratified on time [18]. Husain, herself a deaf woman, she expressed her feelings about deaf that it is more stigmatized and threatening term and has different negative meanings and perceptions as compared to hearing loss, the purpose to change people's perception from deaf toward hearing loss means problem is manageable and it is only due to a disease or misshapenness [19].

According to another perspective, some people perception is something different about them. Likewise, if they can't hear and speak so they can't understand while they can easily understand messages through non-verbal communication. Despite this fact they face various difficulties and barriers due to hearing loss. Sense of hearing is one major sources of getting information and knowledge while people with this kind of disability face difficulty. When they don't express their feelings and emotions adequately they feel frustrated and sometimes become aggressive. After that they develop some behavioral problems which are considered unacceptable by parents and society. Iftikhar and Yasmeen conducted a study on parents to identify parents' perception about disability, $44 \%$ parents perceived it cause of anxiety, $66 \%$ perceived them social burden, $74 \%$ perceived an economical stressor and $84 \%$ reported deaf children increased their worries [20]. Although it is very difficult for parents but rejection and ignorance is unacceptable for children. Then they feel deprived and become sensitive toward criticism, such kind of negative feedback creates distress and emotional disturbance which gradually turns into psychiatric illnesses [21-23].

The scope of the present study concentrates over the prevalence of emotional disturbance among intellectually disabled and children with loss of hearing. Intellectual disability and hearing loss are usually considered invisible disabilities. Both kinds of children mostly experience various medical complications and psychological problems. The common psychological problems are developmental, emotional, social and behavioral. Although, children with hearing impairment and intellectual disability are different according to the nature of disability but more or less equally contribute in creating emotional disturbance. Medical and psychological problems initially cause emotional disturbances and gradually they may change into psychiatric disorders. Present study also aims to investigate the prevalence of emotional disturbance among children with hearing impairment and intellectually disabled.

\section{Materials and Methods}

\section{Participants}

In present study more than 90 children were approached. After data scrutiny 67 children were included and other participants were excluded due to incompletion of sample criteria. In reaming sample $47.76 \%$ were children with hearing impairment and $52.24 \%$ were intellectually disabled. Male children were 47 and females were 20 . All participants were taken from lower middle $(\mathrm{n}=31)$ and upper middle class $(n=36) .39$ children were taken from joint family system and 28 were from nuclear family system. Participants' education was nursery to eight grades. Entire sample was collected from different special schools and rehabilitation centers of Karachi, Pakistan. Age range of the entire sample was from 12-18 years. Total sample Mean age was $\mathrm{M}=14.98$ with $\mathrm{SD}=2.02$ years. Mean age of children with hearing impairment was $\mathrm{M}=15.19$ years with $\mathrm{SD}=2.11$ years and mean age of intellectually disable children was $\mathrm{M}=14.74$ years with $\mathrm{SD}=1.95$ years respectively.

\section{Study inclusion and exclusion criteria}

In this study, children with hearing impairment or intellectual disability were included only. Those children who have both the disabilities (i.e. hearing impairment and intellectual disability) or children with multiple disabilities were excluded from the study. Children below age 12 and above age 18 years were not included in the study. Further, only diagnosed children with hearing impairment or intellectual disability were included in the study. Moreover, those children who did not complete the test were also excluded.

\section{Data Collection Tools}

Initially, permission was taken from the authorities. They were further briefed about the purpose of the current study. It was assured that gathered information would be confidential and your identity will never be disclosed. After that demographic information was gathered (i.e. age, education, income group \& family structure). Further, interview was conducted with parents in order to get depth information about the history of child's problem such as, duration of illness, severity of problems, previous treatments, school history, family and friendship history. Moreover, examiner instructed the participants properly. Likewise, examiner provided paper and pencil to a child and it was asked to the child to draw a human figure drawing on this paper. The instructions were given according to the manual and then Human Figure Drawing test was administered individually in order to explore emotional disturbance in sample [24].

\section{Statistics analysis}

Data was scored according to manual of human figure drawing test and it was transferred into excel sheet for statistical analysis. Statistical Packages for Social Science (SSPS, Vol.12) was used to examine the mean, standard deviation, and t-test to investigate the prevalence of emotional difference between intellectually disabled and children with hearing loss.

\section{Results}

In whole sample $47.76 \%$ were children with hearing impairment and $52.24 \%$ were intellectually disabled. Male children were $70.14 \%$ and females were $29.85 \%$ with joint family system $58.21 \%$ and nuclear system $41.79 \%$. Children from lower middle income group were $46.27 \%$ and upper middle group were $53.73 \%$. Results reported that emotional disturbance among children with hearing impairment and intellectually disabled was found statistically significant. Children with hearing impairment were found significantly different from intellectually disabled on the protocols of human figure drawing test i.e. shading of face, body and limbs $(\mathrm{t}=7.905 ; p<0.000)$, shading of hands or neck (11.574; $p<0.000)$, transparencies $(\mathrm{t}=0-2.450 ; p<0.017)$, grossed eyes $(\mathrm{t}=4.532 ; p<0.000)$, teeth $(\mathrm{t}=2.785 ; p<0.007)$, long arms $(\mathrm{t}=2.306 ; p<0.024)$ and protocol of arms clinging to sides of body $(\mathrm{t}=3.083 ; p<0.003)$. Further results reported, children with intellectual disability were found significantly different from children with hearing impairment on the protocols of human figure drawing test i.e. poor integration of body parts $(\mathrm{t}=-5.340 ; p<0.000)$, monster or grotesque figure $(\mathrm{t}=-3.033 ; p<0.003)$ and omission of body parts such as eyes $(\mathrm{t}=-2.534 ; p<0.014)$, nose and mouth $(\mathrm{t}=-3.524 ; p<0.002)$, arms and 
legs $(\mathrm{t}=-5.733 ; p<0.000)$, feet $(\mathrm{t}=-6.125 ; p<0.000)$, neck $(\mathrm{t}=-6.772 ; p$ $<0.000)$ and omission of whole body $(\mathrm{t}=-3.524 ; p<0.001)$ (Tables 1-3).

\section{Discussion}

Present study findings reported children with hearing impairment and intellectual disability were found significantly emotionally disturbed. Where the children with hearing loss were found significantly emotionally disturbed the children with intellectual disability were also found significantly emotionally distressful. These findings are consistent with the findings of previous study conducted by Fletcher et al. [9]. Further, analysis reveals that significant level of emotional disturbance in hearing impaired and intellectually disabled children is an indication of various psychiatric disorders which may develop recently or later on. Emotional disturbance among these children reveals through various factors. According to Simmons, et al. prevalence of emotional problems is higher in children with hearing or intellectual disability and it is strongly associated with emotional distress [4]. Further, Reiss et al. conducted a study on special children and they explored, children are found to be at $20 \%$ to $30 \%$ risk of emotional disturbance [16]. Smith also agreed that intellectually or children with hearing loss perceived high risk of psychological problems [25].

Present study findings reported children with hearing impairment are found significantly different from the intellectually disabled children over some emotional indicators. For example, emotional indicators of shading represent high manifestation of anxieties, poor self-concept and guilt feelings over inadequate aggressive behaviors or sexual impulses. This may lead to various anxiety disorders. Actually, anxieties among children with hearing impairment usually reveal when their needs and wishes are not fulfilled adequately by parents or others then they become depressed. Difficulty in communication skills or speaking deficiency also does matter in emotional disturbance. When they feel difficulties in hearing and could not communicate their messages to others properly then they feel deprived and approach the worlds according to their own perspectives. Sometimes this becomes very easy for them to access simple ideas of others and they respond properly but sometimes they cannot understand some complex messages of others, and then they started to live inferiors and this intensity becomes

\begin{tabular}{|c|c|c|c|c|}
\hline Demographic information & Category & N & $\begin{array}{c}\text { Children } \\
\text { with } \\
\text { hearing } \\
\text { Impairment } \\
\mathbf{( 4 7 . 7 6 \% )}\end{array}$ & $\begin{array}{c}\text { Children } \\
\text { with } \\
\text { intellectual } \\
\text { disability } \\
\mathbf{( 5 2 . 2 4 \% )}\end{array}$ \\
\hline Sex & Male & 47 & $26(32)$ & $21(35)$ \\
\hline Family structure & Female & 20 & $6(32)$ & $14(35)$ \\
\hline & Joint & 39 & $18(32)$ & $21(35)$ \\
\hline Income group & Lower Middle & 31 & $14(32)$ & $17(35)$ \\
\hline Education & Upper middle & 36 & $20(32)$ & $16(35)$ \\
\hline & Nursery & 31 & $6(32)$ & $25(35)$ \\
\hline & KG 1\&2 & 13 & $6(32)$ & $7(35)$ \\
\hline & Primary & 15 & $12(32)$ & $3(35)$ \\
\hline Common complaints in & Middle & 8 & $8(32)$ & $0(35)$ \\
\hline children reported by their & Impulsivity & 50 & $21(32)$ & $29(35)$ \\
\hline parents & Anxiousness & 46 & $18(32)$ & $28(35)$ \\
\hline & Aggression & 56 & $27(32)$ & $29(35)$ \\
\hline & Stubbornness & 54 & $26(32)$ & $28(35)$ \\
\hline
\end{tabular}

Table 1: Descriptive statistics for age, education and behavioral symptoms of children with hearing impairment and intellectual disability $(\mathrm{N}=67)$.

\begin{tabular}{|c|c|c|c|c|c|}
\hline Age & N & Minimum & Maximum & M & SD \\
\hline Children with HI & 32 & 12 & 18 & 15.19 & 2.101 \\
\hline Children with ID & 25 & 12 & 18 & 14.74 & 1.945 \\
\hline Total & 67 & 12 & 18 & 14.96 & 2.018 \\
\hline
\end{tabular}

Table 2: Descriptive statistics for Age $(\mathrm{N}=67)$.

increase when they compare themselves with their siblings and other people who have ability of hearing and speaking properly [26]. Poor coordination, impulsivity, physical awkwardness, physical inadequacy and confusion of lateral dominance are found common in children with hearing loss. Moreover, indications of emotional disturbance reveal through acting out behaviors, impulsivity and immaturity and poor judgments and these are the manifestations of psychological problems like paranoid ideation and psychosis [24].

On the other hand, children with intellectual disability were also found significantly emotionally disturbed as compared to children with hearing impairment over some emotional indicates. For example, emotional indicators of poor integration of body parts are instability, poor coordination and impulsivity which represent indications of psychosis and mania. Emotional indicators of short or long arms or arms clinging to body are difficulty to access world, rigidity, aggressiveness and need for love and affection. In addition, emotional indicators of genitals manifest aggression, acute body anxiety and poor impulses which are also indications of psychosis. Further, guilt feelings, feeling of inadequacy, guilt over failure to act correctly are the representations of delinquent behaviors and psychosomatic complaints. The common emotional indicators of omissions are shy and withdrawal behaviors, feeling of immobility, helplessness, feelings of inadequacy, poor inner control, body anxiety, psychomotor retardation, intellectual deficit, guilt over hostility or sexuality and intense anxiety and insecurity which are the indications of various psychiatric disorders [24].

In short, protocols represent both groups of disabilities are at high risk of psychological problems. Analysis reveals that emotional disturbance among both groups of children is due to variety of reasons. For example, psychosocial stressors, cognitive deficits and dependency on care givers are the major problems of disabled children. Intellectual functioning, hearing problems, poor integration of knowledge and lack of understanding are the major causes of emotional disturbance in these children. Sometimes it can be due to traumatic experience like stigmatization, criticism and societal rejection and sometimes it becomes due to high risk of sexually and physically abuse [27]. These problems affected their emotional well-being badly and usually they become depressed [28]. These factors become continuous stressors of their lives and mostly these factors cause frustration which gradually changes into aggression. Aggression outburst or hostile behaviors are the clinical representations of some psychiatric disorders and if they are not treated, they become severe and that time hospitalization is recommended usually [29].

\section{Conclusion}

It is concluded that prevalence of emotional disturbance is statistically significant among children with intellectual deficit and children with hearing impairment. This prevalence rate of emotional disturbance is very alarming and this can be a high risk factor of various psychiatric disorders in disabled children. It also creates various behavioral problems that affect negatively children's daily life functioning or activities. These problems should manage easily when free treatment facilities, opportunities of rehabilitations centers, vocational and occupational trainings would be available. These facilities can be very helpful for the disabled children to perform or 
Citation: Abbas Q (2016) Prevalence of Emotional Disturbance in Children with Hearing Impairment and Intellectual Disability. J Psychiatry 19: 350 doi:10.4172/2378-5756.1000350

Page 4 of 5

\begin{tabular}{|c|c|c|c|c|c|c|}
\hline HFD Protocols & \multicolumn{2}{|l|}{ Emotional Indicators } & M & SD & $\mathbf{t}$ & $\mathbf{p}$ \\
\hline \multirow{2}{*}{ Poor integration body parts } & \multirow{2}{*}{ Poor coordination, instability \& immaturity } & CWHI & 0.22 & 0.42 & \multirow{2}{*}{-5.34} & \multirow{2}{*}{0} \\
\hline & & CWID & 0.77 & 0.426 & & \\
\hline \multirow{2}{*}{ Shading of face, body or limbs } & \multirow{2}{*}{ Body anxieties, poor self-concept \& } & CWHI & 0.97 & 0.177 & \multirow{2}{*}{7.905} & \multirow{2}{*}{0} \\
\hline & & CWID & 0.29 & 0.458 & & \\
\hline \multirow{2}{*}{ Shading of hands or neck } & \multirow{2}{*}{ Masturbation \& guilt feelings \& impulses } & $\mathrm{CWHI}$ & 0.91 & 0.296 & \multirow{2}{*}{11.574} & \multirow{2}{*}{0} \\
\hline & & CWID & 0.09 & 0.284 & & \\
\hline \multirow{2}{*}{ Gross asymmetry of limbs } & \multirow{2}{*}{ Impulsivity, physical inadequacy } & CWHI & 0.34 & 0.483 & \multirow{2}{*}{0.766} & \multirow{2}{*}{0.447} \\
\hline & & CWID & 0.26 & 0.443 & & \\
\hline \multirow{2}{*}{ Transparencies } & \multirow{2}{*}{ Aggression, hyperactivity } & CWHI & 0.06 & 0.246 & \multirow{2}{*}{-2.45} & \multirow{2}{*}{0.017} \\
\hline & & CWID & 0.29 & 0.458 & & \\
\hline \multirow{2}{*}{ Grossed eyes } & \multirow{2}{*}{ Poor judgment, sign of rebellion \& anger } & $\mathrm{CWHI}$ & 0.44 & 0.504 & \multirow{2}{*}{4.532} & \multirow{2}{*}{0} \\
\hline & & CWID & 0.03 & 0.169 & & \\
\hline \multirow{2}{*}{ Teeth } & Aggression out burst & $\mathrm{CWHI}$ & 0.44 & 0.504 & 2785 & م007 \\
\hline & Acting out behavior & CWID & 0.14 & 0.355 & 2.185 & 0.001 \\
\hline Short arms not equal to waistline & Difficulty to annroach world \& others & CWHI & 0.41 & 0.499 & 1863 & 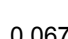 \\
\hline strort armis hol equal to walstinte & 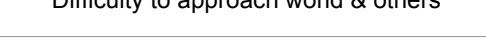 & CWID & 0.2 & 0.406 & 1.000 & 0.001 \\
\hline Iona orme & Nered for lou and offoction & CWHI & 0.34 & 0.483 & 2306 & 0021 \\
\hline Long arms & Need for love and aftection & CWID & 0.11 & 0.323 & 2.306 & 0.024 \\
\hline & & $\mathrm{CWHI}$ & 0.22 & 0.42 & 3083 & 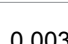 \\
\hline Arms clıngıng to sides of body & Rıgıdity, Intlexıbility \& poor control on selt & CWID & 0 & 0 & 3.083 & 0.003 \\
\hline 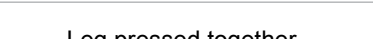 & & CWHI & 0 & 0 & 0956 & $02132>0$ \\
\hline Leg pressed together & Sexual Inadequacy & CWID & 0.03 & 0.169 & -0.956 & 0.343 \\
\hline Monetoror arotosoun fiaure & Ambiquitu indicotion of noushocic & CWHI & 0 & 0 & 3023 & م00? \\
\hline Monster or grotesque igure & Ambiguity, inalcation of psycnosis & CWID & 0.23 & 0.426 & -3.033 & 0.003 \\
\hline Rain cloud three or more fiaure & ow intellectual functioning & CWHI & 0 & 0 & -1372 & 0175 \\
\hline Ram, cioud, miree or more ilgure & Low intellectual iunctioning & CWID & 0.06 & 0.236 & -1.312 & 0.170 \\
\hline Omiccion of avec & Refucal to face world \& eccane into fantacy & CWHI & 0 & 0 & 2534 & 0014 \\
\hline Umission or eyes & Rerusal to tace worid \& escape into tantasy & CWID & 0.17 & 0.382 & -2.534 & 0.014 \\
\hline Omicsion of noce/mouth & Wlithdrawal \& helplecsnecs & CWHI & 0.03 & 0.177 & -3198 & 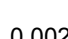 \\
\hline Umission or nose/moum & Vvitnarawal a nelplessness & CWID & 0.31 & 0.471 & -3.198 & 0.002 \\
\hline Omission of bodv & Motor retardation \& intellectual deficits & CWHI & 0 & 0 & & \\
\hline & Motor retardatıon \& intellectual detıcıts & CWID & 0.29 & 0.458 & -3.524 & 0.001 \\
\hline Omicsion of arms \& legs & Guilt hoctility anxiety \& sexuality & CWHI & 0 & 0 & -5733 & \\
\hline Omission of arms \& legs & Gullt, hostility, anxiety \& sexuality & CWID & 0.51 & 0.507 & $-5 . / 33$ & 0 \\
\hline Omingion of fol $\mathrm{s}$ & 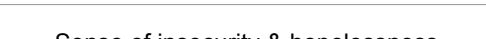 & CWHI & 0.03 & 0.177 & 6105 & 0 \\
\hline Umission of teet & Sense of Insecurity \& hopelessness & CWID & 0.6 & 0.497 & -6.125 & 0 \\
\hline 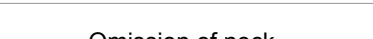 & Immaturitu 8 imnulaivitu & CWHI & 0.16 & 0.369 & 6770 & 0 \\
\hline Umission of neck & Immaturity \& impuisivity & CWID & 0.8 & 0.406 & -6.172 & 0 \\
\hline
\end{tabular}

$\mathrm{Df}=2,65$; HFD= Human Figure Drawing Test; CWHI= Children with Hearing Impairment; CWID= Children with Intellectual Disability

Table 3: Descriptive and t-test statistics for Children with Hearing Impairment (CWHI) and Children with Intellectual Disability (CWID) on variable of emotional disturbance $(\mathrm{N}=67)$.

utilize other abilities that are blessed under proper supervision and guidance and they can live healthy life. Further, to spread awareness in societies as well as parents psycho-education can be very effective to reduce disable children's level of emotional disturbance.

\section{References}

1. WHO, World Bank (2011) World Report on Disability. WHO Library Cataloguingin-Publication Data.

2. Ministry of women development, Social welfare and special education (2002) National Policy for Persons with Disabilities. Government of Pakistan.

3. Spitzer RL (1987) DSM-III-R, Chapter 3: Disorders usually first evident in infancy, childhood, or adolescence: mental retardation. Am Psych Assoc, Washington, DC

4. Simmons JQ, Tymchuk AJ, Valente M (1974) Treatment and care of the mentally retarded. Psychiatric Annals 4: 38- 69

5. Bashir R (2005) Students with hearing impairment in inclusive classrooms $2^{\text {nd }}$ International Conference on Inclusive Education: Innovations in Inclusive School Development, Hong Kong.
6. Khatoon A (2003) A historical and evaluative study of special. Special Education Department, University of Karachi, Karachi.

7. Cadman D, Boyle M, Szatmari P, Offord DR (1987) Chronic illness, disability and mental and social well-being: Findings of the Ontario Child Health Study. Pediatrics 79: 805-813.

8. Einfeld SL, Tonge BJ (1996) Population prevalence of psychopathology in children and adolescents with intellectual disability: II. Epidemiological findings. J Intellect Disabil Res 40: 99-109.

9. Fletcher R, Loschen E, Stavrakaka C, First M (2007) Intellectual disabilities In: Diagnostic manual-intellectual disability: A clinical guide for diagnosis of mental disorders in persons with intellectual disability, NADD Press, New York.

10. Baker BL, McIntyre LL, Blacher J, Crnic K, Edelbrock C, et al. (2003) Preschool children with and without developmental delay: behaviour problems and parenting stress over time. J Intellect Disabil Res 47: 217-230.

11. Adewuya AO, Oseni SB, Okeniyi JA (2006) School performance of Nigerian adolescents with epilepsy. Epilepsia 47: 415-420.

12. O'Connell ME, Boat T, Warner KE (2009) Preventing mental, emotional, and behavioral disorders among young people. National Academies Press, Washington. 
Citation: Abbas Q (2016) Prevalence of Emotional Disturbance in Children with Hearing Impairment and Intellectual Disability. J Psychiatry 19: 350 doi:10.4172/2378-5756.1000350

Page 5 of 5

13. Menolascino $F(1976)$ Therapy of the mentally retarded. Current Psycho Therapy 16: 9-19.

14. Lidz T (1983) The Juvenile. In: The Person: His and Her Development Throughout the Life Cycle. Basic Books, New York.

15. Mogasale VV, Patil VD, Patil NM, Mogasale V (2012) Prevalence of specific learning disabilities among primary school children in a South Indian city. Indian J Pediatr 79: 342-347.

16. Reiss S, Levitan GW, Szyszko J (1982) Emotional disturbance and mental retardation: diagnostic overshadowing. Am J Ment Defic 86: 567-574.

17. Batool BS, Shehbaz SF (2008) A study of the perceptions of the teachers of HIC about the capabilities of HIC. Department of Special Education, University of Punjab, Lahore.

18. Kent BA (2003) Identity issues for hard-of-hearing adolescents aged 11, 13 and 15 in mainstream settings. J Deaf Stud Deaf Educ 8: 315-324.

19. Husain Z (2008) A study of self image of deaf community in Lahore. Department of special education, University of Punjab, Lahore.

20. Iftikhar S, Yasmeen M (2009) A study of stress experience by the parents of HIC. Department of special education, University of Punjab, Lahore.

21. Akram B, Bashir R (2012) Special Education and Deaf Children in Pakistan: An Overview. J Elementary Edu 22: 33-44.
22. Willis RG, Vernon M (2002) Residential psychiatric treatment of emotionally disturbed deaf youth. Am Ann Deaf 147: 31-37.

23. Hamerdinger S, Hill E (2005) Serving Severely Emotionally Disturbed Deaf Youth:A Statewide Program Model. JADARA 38: 1-30.

24. Koppitz EM (1968) Psychological evaluation of children's human figure drawings. Grune \& Stratton, New York.

25. Smith E (1976) Psychotherapy with the mentally retarded children Psychoanalytic Study of the Child, 31: 3- 514.

26. Umar M, Muhammad F (2007) Psychological problems faced by adolescents boys with hearing impairment. Department of Special Education, University of Punjab, Lahore.

27. Ammerman RT, Hersen M, VanHasselt VB, Lubetsky MJ, Sieck WR (1994) Maltreatment in psychiatrically hospitalized children and adolescents with developmental disabilities: Prevalence and correlates. J Am Acad Child Adoles Psychiat 33: 567-576.

28. Mathos KK, Broussard ER (2005) Outlining the concerns of children who have hearing loss and their families. J Am Acad Child Adolesc Psychiatry 44: 96-100.

29. Cowley A, Newton J, Sturmey P, Bouras N, Holt G (2005) Psychiatric inpatien admissions of adults with intellectual disabilities: Predictive factors. Am J Ment Retard 110: 216-225. 